\title{
A revised taxonomy of the ammonoid genus Desmoceras from Japan and southern Sakhalin
}

\author{
By Tatsuro Matsumoto, M. J. A., ${ }^{*), ~}{ }^{\dagger)}$ and Tamio NishidA **) \\ (Contributed by Tatsuro Matsumoto, м. J. A.)
}

\begin{abstract}
Based on the stratigraphically well sorted material from Japan and southern Sakhalin, the ammonoid species belonging to the genus Desmoceras are classified as follows in ascending order: $D$. latidorsatum (Michelin) (Middle to mid-Upper Albian), D. dawsoni shikokuense (Yabe and Shimizu) (Upper Albian), D. kossmati Matsumoto (uppermost Albian-Lower Cenomanian), D. japonicum Yabe (uppermost Albian-Cenomanian), and D. ezoanum Matsumoto (mid-Upper Cenomanian-mid-Lower Turonian). D. japonicum can be subdivided into the earlier and later subspecies. D. poronaicum Yabe is a junior synonym of $D$. japonicum. Despite the scarcely ornamented shell, each taxon can be defined by its own characters.
\end{abstract}

Key words: Ammonoidea; Desmoceras; Cretaceous; Albian; Cenomanian; Turonian.

Introduction. Since the pioneer work of Yabe, ${ }^{1)}$ several species of the genus Desmoceras Zittel, 1885 ${ }^{2)}$ have been described from Japan and southern Sakhalin (see Fig. 1). Recently we have restudied the available material and noticed some points to be revised. In this paper the results are presented concisely.

Note on subgeneric taxonomy. Desmoceras (Desmoceras) shows a depressed and subquadrate whorl section. The subgenus Desmoceras (Pseudouhligella) Matsumoto, 1938 ${ }^{3)-5)}$ has been used for the species with oval whorl section and biconcave constrictions and lirae in the middle to late growth stages. These two subgenera have been generally approved, as shown by Wright. ${ }^{6)}$ In this paper they may be indicated as Desmoceras (D.) and Desmoceras (P.) or $D$. (D.) and $D$. (P.) for brevity.

The shell surface of Desmoceras is not completely smooth. In the favorably preserved specimens, very weak and fine lirae or subcostae are discernible in every species in addition to the periodic constrictions and associated flares.

\section{Desmoceras (D.) latidorsatum (Michelin).}

In addition to the specimen reported by Matsumoto, 1954 ${ }^{5)}$ (p. 248, pl. 6, fig. 5) from the

\footnotetext{
*) c/o The Kyushu University Museum, 6-10-1, Hakozaki, Higashi-ku, Fukuoka 812-8581, Japan.

**) Faculty of Culture and Education, Saga University, 1, Honjo-machi, Saga 840-8502, Japan.

$\dagger$ Correspondence to: T. Matsumoto.
}

Shuyubari area, we have treated two specimens from the lower part of the Upper Albian Member My1c of the Lower Yezo Group on the Sounnai route of the Soeushinai area: GK. H8497 and M. Hayashi's Coll. no. 41 (now kept in the Nakagawa Museum). The former was contained in a large nodule, together with Hysteroceras orbignyi Spath etc.

\section{Desmoceras (P.) dawsoni shikokuense} (Yabe and Shimizu).

The holotype, IGPS.35154, was illustrated by Yabe, $1927^{7)}$ (pl. 3, fig. 10), without description. It is nomenclaturally approved by the description by Yabe and Shimizu (in Shimizu, 1931, ${ }^{8}$ p. 26, pl. 4, figs. 5, 6) under Beudanticeras shikokuense. On account of the difference in sutural pattern, this generic assignment was questionable.

Much later, Nakai and Matsumoto $(1968)^{9)}$ gave a revised description on the basis of numerous specimens, including the holotype, from the Upper Albian Fujikawa Formation of Shikoku under D. (P.) dawsoni shikokuense. It is distinguished from $D$. dawsoni dawsoni (Whiteaves, 1900) ${ }^{10)}$ by the smaller size of the adult shell and less flexuosity of the constrictions. In both subspecies the whorl section is narrowly subelliptical with a rounded umbilical margin. Its suture is well shown in some specimens from Shikoku (see Nakai and Matsumoto, 1968, ${ }^{9)}$ fig. 2). This subspecies seems to occur also in the Upper Albian strata of Hokkaido, but the available specimens are secondarily distorted. We do 


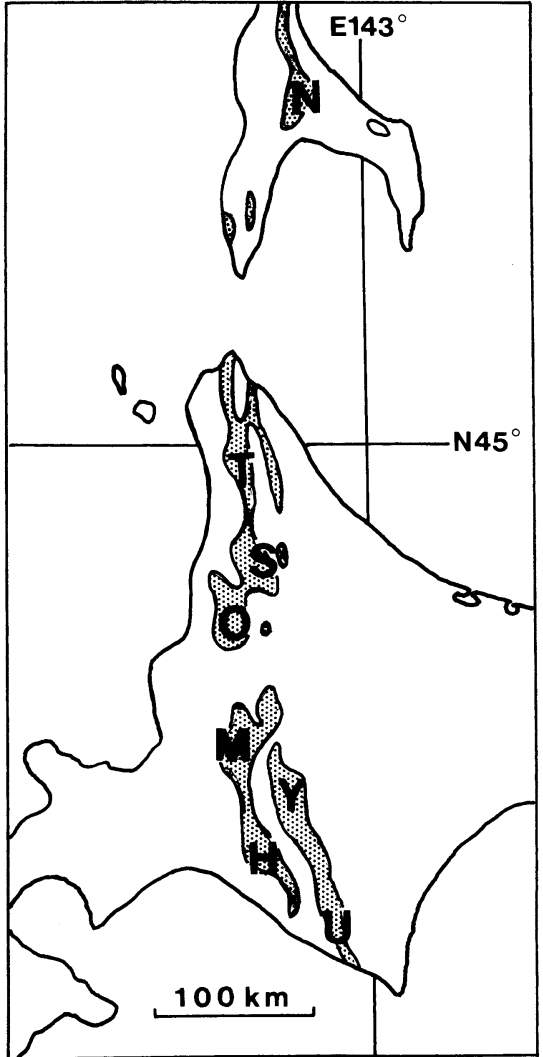

Fig. 1. Map of southern Sakhalin and Hokkaido (main part), showing the distribution of the Yezo Group. The area where the mid-Cretaceous (Upper Albian-Lower Turonian) series has been intensively studied are indicated; from north to south: $\mathrm{N}=$ Naiba [Naibuchi], $\mathrm{T}=$ Teshio Nakagawa, $\mathrm{S}=$ Soeushinai, $\mathrm{O}=$ Obirashibe valley, $\mathrm{M}=$ Mikasa and vicinities, $\mathrm{Y}=$ Yubari Mountains (Shuyubari or Oyubari), $\mathrm{H}=$ Hobetsu, $\mathrm{U}=$ Urakawa and vicinity.

not agree with Kawabe and Haggart ${ }^{11)}$ in their assignment of this subspecies to $D$. (P.) poronaicum.

\section{Desmoceras (P.) kossmati Matsumoto. ${ }^{4), 5)}$}

The lectotype (UMUT MM6667 = GT. I-2551) was collected at Loc. N507p, Imano-sawa of the Naibuchi [= Naiba] area, S. Sakhalin. Its original horizon is at about the Albian-Cenomanian transition. In Hokkaido numerous specimens have been obtained from the Lower Cenomanian strata of the Soeushinai and Shuyubari areas, and also some from the uppermost part of the Albian in the same areas.

This species is characterized by the oval whorl section, which is compressed in youth and broadens with growth, resulting the whorl of later growth stage nearly as broad as high in some individuals. The shell size is generally small, e.g. about $40 \mathrm{~mm}$ diameter at the end of the phragmocone. The umbilical shoulder appears to be angular or subangular or even subrounded, falling into vertical wall. Constrictions occur rather infrequently and are better marked on the outer part of the whorl. They show forward biconcave curvature, although the concavity at the umbilical margin is less distinct.

To show the change of shell characters with growth and also some extent of variation, selected examples are illustrated in Fig. 2A-C in addition to the previous ones. ${ }^{5)}$

\section{Desmoceras (D.) japonicum Yabe. ${ }^{1)}$}

This was described originally as Desmoceras dawsoni Whiteaves var. japonica Yabe ${ }^{1)}$ (1904, p. 35, pl. 5, figs. 3,4$)$ and later ranked as a distinct species. ${ }^{4)}$ Its holotype, UMUT MM7574 from Mikasa (Fig. 3B), is a nearly full grown shell, about $120 \mathrm{~mm}$ diameter, but its very apertural margin is destroyed. Some of the specimens from the Soeushinai area exhibit the apertural part, which has a remarkably forward projected venter and a highly sigmoidal margin of the flank, with well marked constrictions and accompanied flares behind. However, whether there is dimorphic (or sexual) difference in the apertural character or not is yet undecided. Moreover, whether a similar feature is maintained in other species of Desmoceras or otherwise has to be investigated further.

Except for the globular shape in very young stage (see Matsumoto, 1954, ${ }^{5)}$ figs. 5, 6), the shell form of young stage (Fig. 2D) is essentially similar to that of the adult one. The whorl is nearly parallel-sided and the venter is evenly rounded. The umbilical wall is perpendicular to the plane of coiling, while the umbilical shoulder appears to be angular or subangular or even subrounded in some specimens.

The wide morphological variation of this species is observed in the material from various parts of the range of this species. For instance, at Loc. R8061 on the middle course of the Shumarinai River (Lower Cenomanian), a number of small shells (less than $25 \mathrm{~mm}$ in diameter) are contained in each of several nodules. They show variable breadth/height ratio even in one and the same nodule.

The difference in the shell size at maturity has been noticed between the specimens from the lower and upper stratigraphic levels. For some reasons small immature shells occur frequently in some cases. Through the intensive field work, we have noticed that young shells occur abundantly in some areas (e.g., the Soeushinai area), while mature shells occur frequently in some other areas (e.g., the upper reaches of the Shirakin-zawa in a part of the Yubari Mountains). Such 

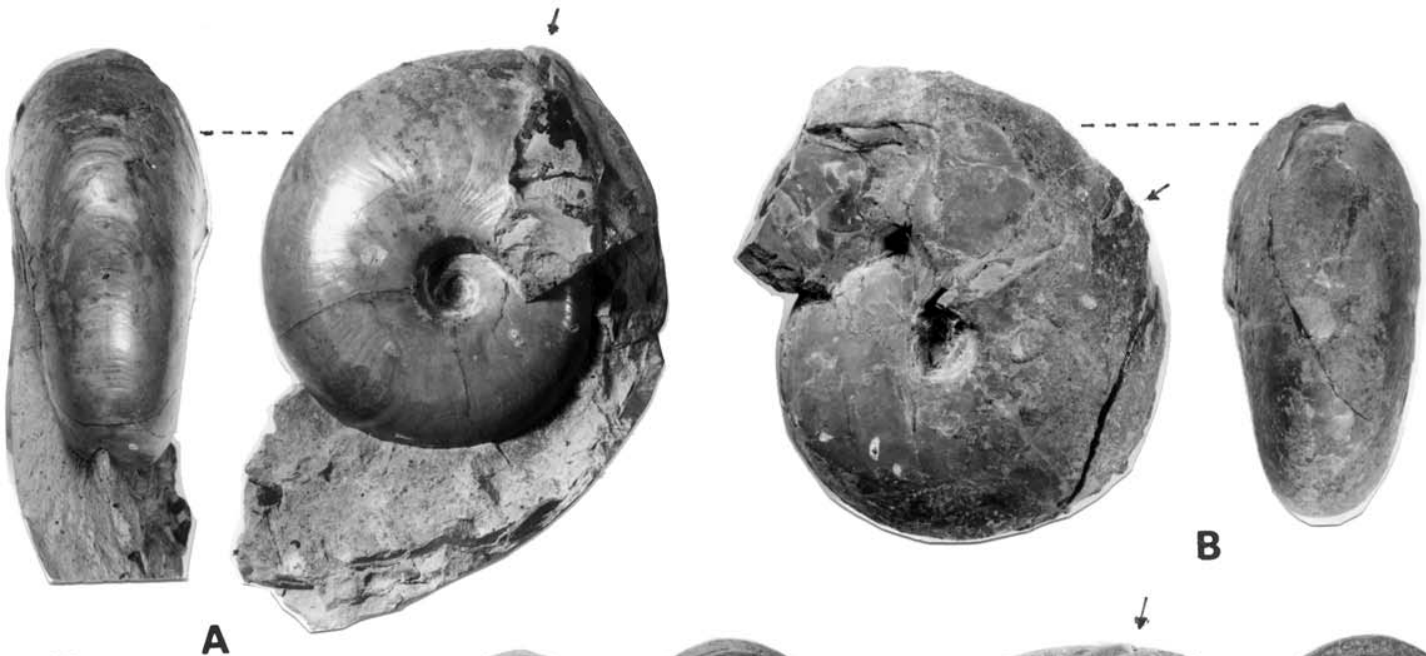

A

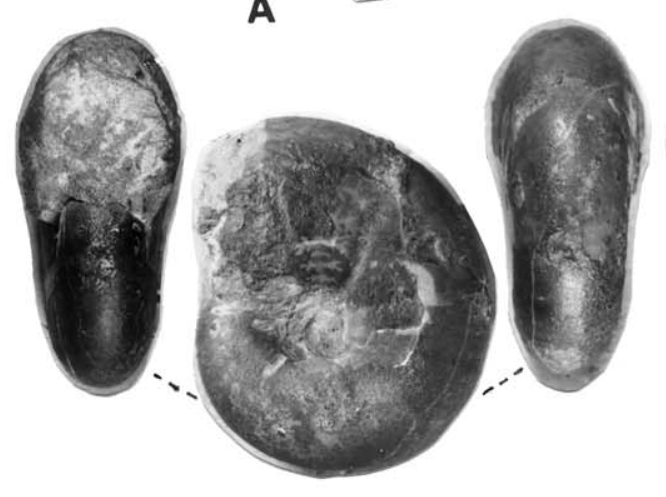

C

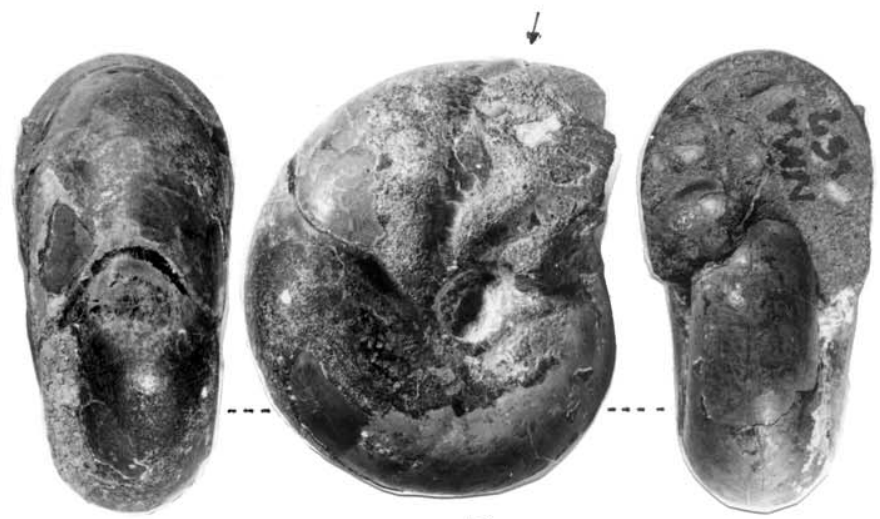

D

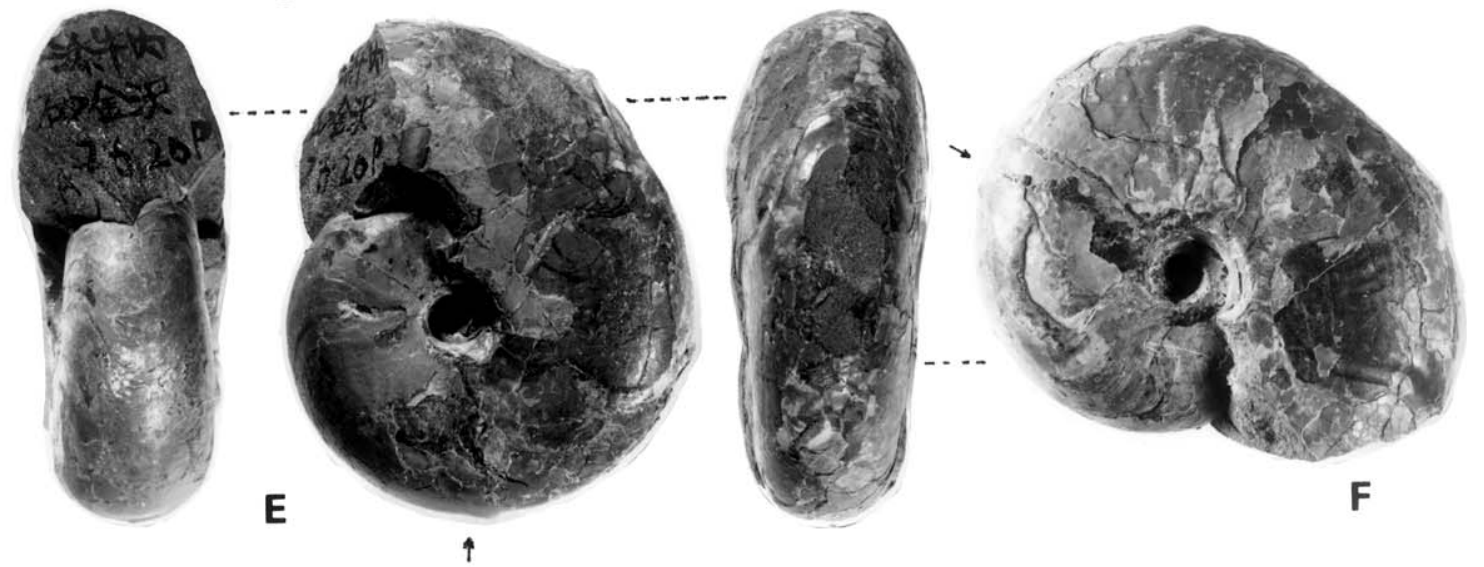

Fig. 2. Selected examples of Desmoceras. A-C. D. kossmati Matsumoto. A: MCM. A345 from Hobetsu, collected by K. Hasegawa at a point $750 \mathrm{~m}$ east from the mouth of the creek called the Penke-wakka-tannenai-zawa. B: GK. H8625 from Loc. R8925p, KyoeiSakin-zawa of the Soeushinai area. C: GK. H8624, a young specimen, magnified × 2, from Loc. R519p2, eastern main branch of the Suribachi-zawa, a tributary of the Sounnai River. D: Desmoceras japonicum Yabe. NM. A157, middle-aged specimen from the Teshio Nakagawa, described by Hayakawa and Nishino, $1999 .{ }^{12)}$ E-F: Desmoceras japonicum minor subsp. nov., GS. G097 from the Kyoei-Sakin-zawa, F is photoed under different lighting to show the weak subcostae or lirae. Figures are natural size, except C. Photos courtesy of M. Noda. In each figure an arrow indicates the position of the last septum. Abbreviations of the repositories: GK. = Geological Collection, the Kyushu University Museum, 6-10-1, Hakozaki, Higashi-ku, Fukuoka 812-8581, Japan; GS. = Geological Collection, Saga University, Honjo-machi, Saga 840-8502, Japan; MCM. = Mikasa City Museum, 1-212-1, Nishikicho, Ikushunbetsu, Mikasa, Hokkaido 068-2111, Japan; NM. = Nakagawa Museum of Natural History, 28-9, Yasukawa, Nakagawa-machi, Hokkaido 098-2626, Japan. 

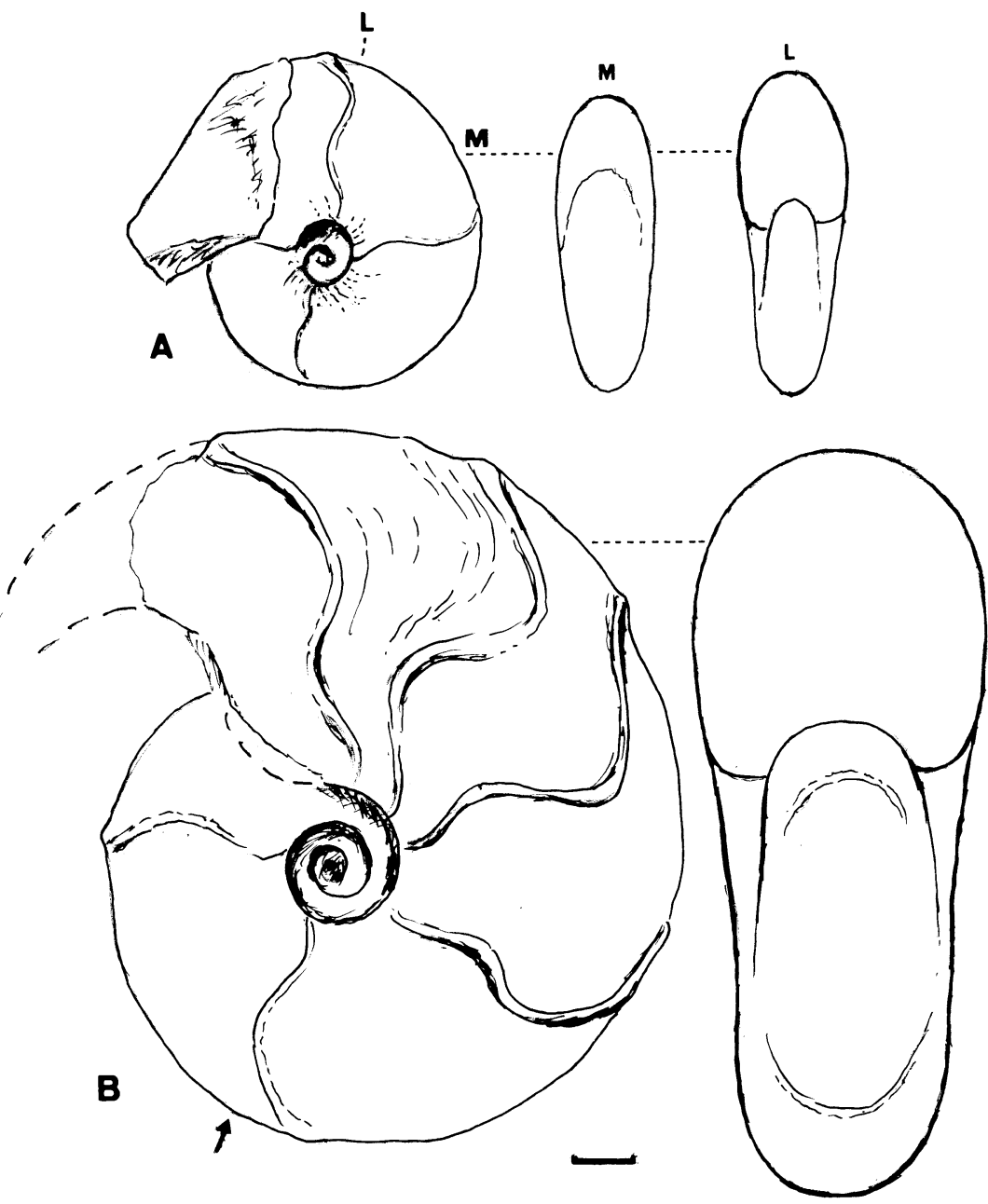

Fig. 3. Diagrammatic figures of the holotypes of A: D. ezoanum Matsumoto and B: D. japonicum Yabe. Scale bar: 10 $\mathrm{mm}$; arrow: end of phragmocone. A is wholly septate. Figures depend on the photos in Matsumoto, 1954, ${ }^{5)} \mathrm{pl} .3$ [19], fig. 1a-c and pl. 1 [17], fig. 7a, b.

difference may be related to the environmental conditions. Keeping this point in mind, we have examined various cases, and, thus we have arrived at the conclusion that even at the late growth stage the specimens from the lower stratigraphic levels (upper Albian and lower Cenomanian) are generally smaller than those from the higher levels (mainly middle part of the Cenomanian Stage). Thus, the subspecies can be proposed as follows:

D. (P.)japonicum japonicum Yabe, 1904 as it is; and D. (P.) japonicum minor subsp. nov. GS. G097 (Fig. $2 \mathrm{E}-\mathrm{F}$ ) is here designated as the holotype of the latter. It came from the Lower Cenomanian Member My3 of the Kyoei-Sakin-zawa. It is $43 \mathrm{~mm}$ in diameter at the end of the phagmocone and its preserved part of the body chamber is about a half whorl.

The holotype of D. poronaicum Yabe, $1904^{1)}$ (p. 39, pl. 6 , figs. 1,2 ) is too small to show clearly the specific characters. However, it is nearly parallel sided, as shown by the photos in Matsumoto ${ }^{5)}$ (1954, pl. 2 [10], fig. $5 a, b)$. Its obliquely cut apertural view by Kawabe and Haggart $^{11)}$ (2003, fig. 6-1, -2) may give an erroneous image. Its record of occurrence by Yabe and the mode of preservation indicate its derivation from the particular fossiliferous layer in the southern part of the Poronai [recently called Horonai] area of Mikasa, where Calycoceras (Newboldiceras) asiaticum occurs. One of us (T. M.) visited there under the guidance of $\mathrm{T}$. Takahashi, who is well acquainted with the fossiliferous 
outcrop. Based on this field evidence and observable characters of the specimens, $D$. poronaicum should be regarded as a junior synonym of $D$. japonicum. Some specimens which were erroneously referred to $D$. poronaicum by Matsumoto ${ }^{5)}$ (1954, pl. 2 [18], figs. 6, 7; pl. 3 [19], fig. 7) should be transferred to D. kossmati.

Incidentally, the forms called $D$. (P.) japonicum mediocompressa and $D$. (P.) japonicum compressior by Matsumoto ${ }^{5)}$ (1954, pp. 257-258) are merely varieties in $D$. (P.) japonicum and these subspecific names are unnecessary.

\section{Desmoceras ezoanum Matsumoto.}

The holotype, UMUT MM6705 (see Fig. 3A in this paper), came from Loc. T8431 of the Nakagawa district. This species ranges from the middle part of the Cenomanian to the lower part of the Turonian Stage in this and other areas of Hokkaido. It is characterized by a narrowly oval whorl section, with nearly flat to slightly convex flanks, converging to the narrowly arched venter. The umbilicus is narrow and surrounded by an angular or subangular shoulder. Its adult shell is fairly large. Its original description ${ }^{4), 5}$ is quite adequate.

Concluding remarks. The above is the concise summary of our restudy of the Desmoceras from Japan and S. Sakhalin. It is different in some respects from the result of the recent study by Kawabe and Haggart (2003), ${ }^{11)}$ who seem to have neglected the characters and stratigraphic position of the two original specimens of $D$. poronaicum Yabe.

Acknowledgements. A number of kind persons helped us for this restudy of Desmoceras. We owe especially to Mr. Koji Hasegawa and Dr. Manabu Kano of the Mikasa City Museum and Dr. Yoshinori Hikida of the Nakagawa Museum of Natural History for the loan of the selected specimens in their care. Professor Kazunari Tanabe and Mr. Yasuhiro Iba helped us for our restudy of the specimens kept in the University Museum, the University of Tokyo. Dr. Masayuki Noda kindly took photos of the specimens shown in Fig. 2. We highly appreciate Dr. Haruyoshi Maeda of the Kyoto University for his kind help to improve the first draft of this paper. Likewise we owe much to Professor Masao Futakami of the University of Kawamura-gakuen for his work as the second referee. Our field works in Hokkaido were carried out under the permission of the Forestry Offices.

\section{References}

1) Yabe, H. (1904) J. Coll. Sci. Imp. Univ. Tokyo 20, 1-45, pl.1-6.

2) Zittel, K. A. (1885) Handbuch der Paläontologie 1, Abt. 2, Lief. 3, 329-522. Oldenbourg, Münich \& Leipzig.

3) Matsumoto, T. (1938) J. Geol. Soc. Japan 45, 13-24, pls. 1-2.

4) Matsumoto, T. (1942) Proc. Imp. Acad. 18, 24-29.

5) Matsumoto, T. (1954) The Cretaceous System in the Japanese Islands, Appendix, 243-311, pls. 1-20 [17-36] Japan Soc. Prom. Sci., Tokyo.

6) Wright, C. W. (1996) Treatise on Invertebrate Paleontology, Part L Mollusca, revised 4, Cretaceous Ammonoidea, 1-362, Geol. Soc. America and Univ. Kansas.

7) Yabe, H. (1927) Sci. Rept. Tohoku Univ. ser. 2, 11, 27-100, pls. 3-9.

8) Shimizu, S. (1931) Sci. Rept. Tohoku Univ. ser. 2, 15, 1-40, pls. 1-4.

9) Nakai, I., and Matsumoto, T. (1968) J. Sci., Hiroshima Univ. ser. C, 6, 1-15, pls. 1-3.

10) Whiteaves, J. (1900) Geol. Soc. Canada Mesoz. Fossils 1 , 263-307, pls. 33-39.

11) Kawabe, H., and Haggart, J. W. (2003) J. Paleont. 77, 314-322.

12) Hayakawa, H., and Nishino, T. (1999) Bull. Nakagawa Mus. Nat. Hist. 2, 1-40

(Received March 26, 2004; accepted May 12, 2004) 